\title{
ANALISIS PGA (PEAK GROUND ACCELERATION) BERDASARKAN DATA GEMPA UNTUK WILAYAH JAKARTA TIMUR MENGGUNAKAN SOFTWARE PSHA
}

\author{
SITI AYU KUMALA \\ DIDIK NUR HUDA \\ MUKHAMAD CANDRA IRAWAN \\ Program Studi Informatika \\ Fakultas Teknik dan Ilmu Komputer Universitas Indraprasta PGRI \\ Jl. Nangka No. 58 C (TB. Simatupang), Tanjung Barat, Jagakarsa, Jakarta Selatan, Daerah Khusus \\ Ibukota Jakarta 12530 \\ E-mail: sitikumala78912gmail.com
}

\begin{abstract}
Abstrack. The purpose of this research was to produce a contour map of ground motion acceleration (hazard map) for exceeded probability of $10 \%$ as an effort to mitigate earthquake tectonics in East Jakarta. This study uses the applied theoretical research method approach using PSHA software. The data used comes from data released from BMKG and the Geological Agency. Based on the map of the acceleration of soil movement (hazard map) in East Jakarta resulting from the PSHA process, for a return period of 500 years (10\% PE 50 years) the PGA value generated is $0,03 \mathrm{~g}-0,15 \mathrm{~g}$. East Jakarta is a fairly stable region with a low level of earthquake hazard. Increasingly to the south and southwest, the PGA value is increasing due to close to subduction and volcanic activity. The PGA value in this study is almost the same as the revision of the Indonesian SNI earthquake map 03-1726-02 in 2010.
\end{abstract}

Keywords. Hazard Maps, Earthquake, PGA, PSHA

\begin{abstract}
Abstrak. Tujuan dalam penelitian ini adalah untuk menghasilkan peta kontur percepatan gerakan tanah (peta hazard) sebagai upaya mitigasi bencana gempabumi tektonik di wilayah Jakarta Timur. Penelitian ini menggunakan pendekatan metode penelitian teoretik terapan dengan menggunakan software Probablity Seismic Hazard Analysis (PSHA) Data yang digunakan berasal dari data yang dirilis dari USGS, BMKG, dan Badan Geologi Kementrian ESDM yang terletak di Bandung. Berdasarkan peta hazard) di wilayah Jakarta Timur yang dihasilkan dari proses PSHA, untuk periode ulang 500 tahun (10\% PE 50 tahun) nilai Peak Ground Analysis (PGA) yang dihasilkan adalah $0,03 \mathrm{~g}-0,15 \mathrm{~g}$ (g adalah percepatan gravitasi). Jakarta Timur merupakan wilayah yang cukup stabil dengan tingkat bahaya gempa bumi termasuk rendah. Semakin ke selatan dan barat daya, nilai PGA semakin naik akibat dekat dengan aktivitas subduksi dan vulkanis. Nilai PGA dalam penelitian ini hampir sama dari revisi peta gempabumi Indonesia SNI03-1726-02 tahun 2012.
\end{abstract}

Kata kunci :Peta Hazard, Gempabumi, PGA, PSHA

\section{PENDAHULUAN}

Bagian Selatan Negara Indonesia memiliki seismisitas tinggi, hal ini disebabkan oleh dinamika tektonik selatan Indonesia yang didominasi oleh gerakan lempeng India-Australia yang bergerak ke utara bertumbukan dengan lempeng Eurasia yang relatif diam. DKI Jakarta adalah salah satu provinsi di Pulau Jawa yang akan merasakan dampak ketika terjadi gempabumi. Meskipun dampak getaran yang dirasakan oleh Provinsi DKI Jakarta tidak begitu besar, namun banyaknya gedung-gedung tinggi dan padatnya penduduk dapat menghambat proses mitigasi bencana ketika terjadi gempabumi. Gedung Universitas PGRI berada di wilayah Administratif Kota Madya Jakarta Timur. Sehingga penelitian ini dilakukan pada wilayah Jakarta Timur. 
Gempabumi adalah peristiwa bergetarnya permukaan tanah karena pelepasan energi secara tiba-tiba akibat dari pecah/slipnya massa batuan di lapisan kerak bumi (Pawirodikromo, 2012). Semakin besar energi yang dilepas semakin kuat gempabumi yang terjadi. Energi dapat dilepaskan dari pusat gempabumi karena telah terjadi akumulasi energi di daerah atau ditempat tersebut, dan karena tegangan maksimum sudah terlampaui maka slip/pecahlah massa batuan, sehingga sebagian energi yang sudah terakumulasi tersebut dilepaskan. Proses penyebaran energi ini berupa perambatan gelombang gempabumi yang terbagi atas dua tahapan, yaitu tahapan dari sumber gempabumi ke lapisan batuan dasar di bawah lokasi yang akan didekati dengan analisis resiko gempabumi dan tahanan dari batuan dasar ke permukaan yang akan didekati dengan analisis respon dinamik tanah.

Metode PSHA dilaksanakan berdasarkan suatu fungsi distribusi probabilitas yang memperhitungkan pengaruh faktor-faktor ketidakpastian dari ukuran, lokasi dan waktu kejadian gempabumi. Dengan menggunakan metode PSHA dapat diketahui tingkat bahaya gempabumi di suatu lokasi yang ditinjau dengan faktor ketidakpastiannya. Penelitian dengan menggunakan PSHA ini diharapkan mampu membantu menentukan tingkat bahaya bencana gempabumi khususnya di Kota Madya Jakarta Timur.

Tujuan penelitian ini untuk menghasilkan peta kontur percepatan gerakan tanah (peta hazard) untuk probabilitas terlampaui $10 \%$ sebagai upaya mitigasi bencana gempabumi tektonik di wilayah Jakarta Timur. Sehingga diharapkan berguna untuk memberikan informasi perencanaan tata ruang dan bangunan kepada pemerintah kota atau pihak lain yang berkepentingan untuk membuat bangunan di Jakarta Timur, sehingga dapat memperkecil resiko akibat pergerakan tanah yang disebabkan oleh gempabumi.

\section{METODE}

Penelitian ini dilakukan untuk daerah Jakarta Timur dan sekitarnya. Penelitian dilakukan pada tahun 2018. Secara kondisi geologi, Jakarta Timur merupakan daerah dengan batuan alluvium seperti tanah lempung/ pasir dan kerikil bukan kategori batuan keras, sehingga sebenarnya tidak terlalu cocok untuk bangunan-bangunan terlalu tinggi. Pada tahap awal adalah pengkajian dan pengambilan data gempa wilayah DKI Jakarta dan sekitarnya dari tahun 1950 2018. Peralatan yang digunakan terdiri dari perangkat keras dan perangkat lunak, antara lain: Komputer (PC) atau laptop, Microsoft Excel 2007, Software Notepad++, Software Z Map 6.0, Software PSHA 7.20 (USGS, 2007), Surfer 11.

Adapun tahapan penelitian dijabarkan secara ringkas sebagai berikut:

1. Tahap Awal

Pada tahap ini, dilakukan pengumpulan data gempa dan geologi Jakarta Timur. Pengumpulan data dilakukan denggan cara meminta data kepada pihak terkait seperti USGS, BMKG dan Badan Geologi.

2. Tahap Analisis Data

Tahap analisis data merupakan tahap inti dimana data yang sudah diperoleh semuanya dianalisis sehingga mendapatkan peta hazard berdasarkan nilai PGA Jakarta Timur akibat gempabumi

3. Tahap Interpretasi

Setelah data dianalisis, hasil disesuaikan dengan kondisi geologi Jakarta Timur. Ada beberapa faktor yang memengaruhi nilai PGA, oleh karena itu hasil analisis tidak bisa serta merta langsung dipakai untuk menentukan daerah resiko gempa. Harus disertai tinjauan geologi lokasi penelitian agar dapat diinterpretasikan sesuai dengan kejadian di lapangan.

4. Tahap Akir

Tahap akhir adalah membuat laporan hasil penelitian dan mempublikasikannya.

Ringkasan tahapan penelitian dapat dilihat dibawah ini. 


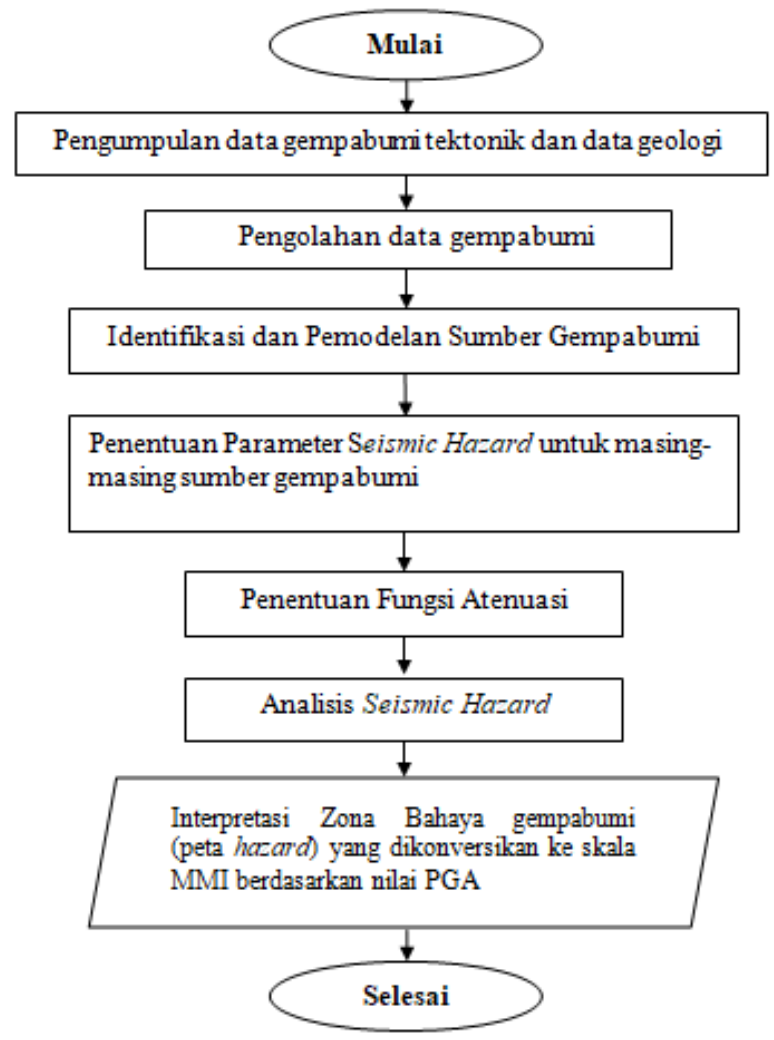

Gambar 1. Diagram Alir Penelitian

Tahap pertama dalam analisis hazard gempabumi adalah mengidentifikasi parameter sumber gempabumi untuk mengetahui sumber gempabumi yang memiliki potensi menghasilkan kejadian gempabumi dan berpengaruh terhadap daerah penelitian. Hasil studi identifikasi parameter sumber gempabumi merupakan data yang akan dipergunakan untuk melakukan PSHA. Parameter sumber gempabumi yang dimaksud meliputi lokasi, magnitude, nilai a dan b, magnitude maksimum dan slip rate, dan fungsi atenuasi (Aldiamar, 2013)

Penelitian ini hanya dibahas tentang PSHA. Proses analisis menggunakan pendekatan Probability Seismic Hazard Analysis (PSHA) adalah memperhitungkan amplitudo maksimum dari beberapa parameter gerakan tanah yaitu percepatan tanah maksimum yang terjadi dalam periode ulang tertentu (Thenhaus dan Campbell, 2003).

\section{HASIL DAN PEMBAHASAN}

Katalog gempabumi yang diambil dari berbagai sumber dikumpulkan sampai mencapai 1.539 kejadian gempabumi untuk area penelitian. Sebelum dilakukan analisis selanjutnya, terlebih dahulu data gempabumi tersebut dikonversi sesuai dengan skala magnitude. Dari data kejadian gempabumi tersebut, wilayah DKI Jakarta dan sekitarnya memiliki kondisi seismisitas yang cukup bervariasi, dilihat dari kejadian gempabumi yang hampir terjadi setiap hari. Selain dipengaruhi dengan aktivitas seismik untuk menentukan nilai dari model sumber gempabumi sangat dipengaruhi juga oleh faktor tatanan tektonik dan geologi pada daerah tersebut. Salah satu daerah yang memiliki aktifitas kegempabumian yang tinggi adalah di daerah sekitar fault dan daerah Java Trench, dan sekitar aktivitas gunungapi Anak Krakatau. (Gambar 2). 


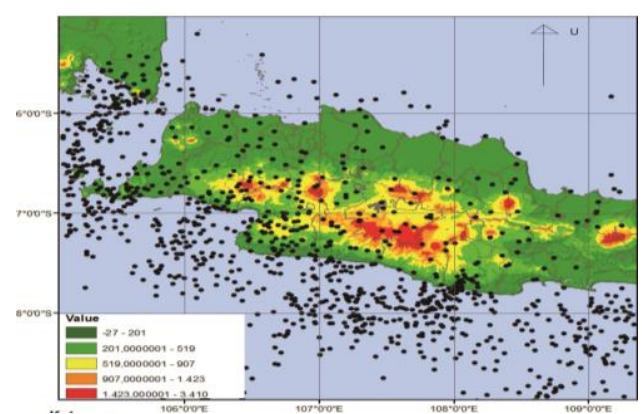

Gambar 2. Peta Seismisitas daerah penelitian

\section{Peak Ground Acceleration (PGA)}

Hasil dari analisis probabilitas seismic hazard dalam penelitian ini adalah nilai Peak Ground Accleration (PGA) pada frekuensi dan periode ulang tertentu yang ditampilkan dalam bentuk peta ataupun kurva hazard. PGA adalah nilai percepatan getaran tanah terbesar yang pernah terjadi di suatu tempat yang diakibatkan oleh gempabumi. Sudah sejak lama nilai percepatan tanah maksimum dijadikan salah satu parameter untuk menyatakan kekuatan suatu gempabumi.

Dengan kata lain semakin besar PGA maka gempabumi yang bersangkutan dianggap semakin kuat, energi besar dan dianggap semakin banyak membuat kerusakan (Prawirodikromo, 2012). National Reseach Council Commite on Earthquake Engineering menyebutkan bahwa pengukuran PGA sangat penting dalam analisis seismic hazard. Hasil dari PGA Jakarta Timur kemudian dikaji berdasarkan kondisi geologi dan keadaan tanah setempat.

Berdasarkan Gambar terlihat bahwa daerah DKI Jakarta memiliki nilai PGA bekisar dari 0,03 $\mathrm{g}-0,15 \mathrm{~g}$ yang hasilnya hampir sama dengan pada revisi peta gempabumi SNI-03-1726-02 (2012) yaitu $0,1 \mathrm{~g}-0,15 \mathrm{~g}$ untuk periode ulang 500 tahun.

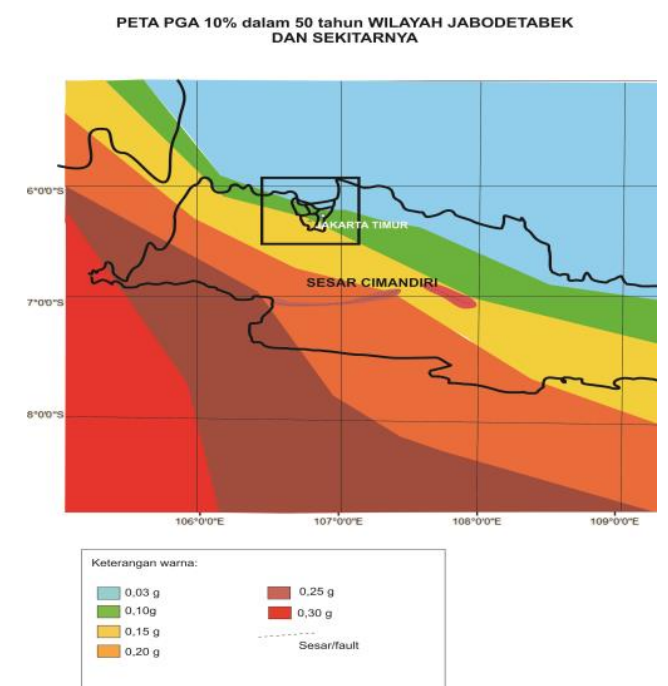

Gambar 3. Peta PGA Daerah Jawa Bagian Barat termasuk di dalamnya kota Madya Jakarta Timur.

Dari hasil analisis yang telah ditampilkan dalam bentuk peta hazard, terlihat bahwa untuk daerah Jakarta Timur, nilai PGA untuk periode ulang 500 tahun yang dihasilkan tidak lebih dari $0,15 \mathrm{~g}$. Hal ini menyatakan bahwa jika resiko yang diakibatkan oleh gempabumi yang terjadi tidak lebih dari skala MMI IV, yaitu terasa di dalam ruangan seperti ada truk besar lewat atau seperti barang berat yang menabrak dinding. Barang-barang yang bergantung bergoyang, jendela dan pintu 
berderik, barang pecah belah pecah, dinding dan rangka rumah berbunyi. (Katz dan Levin, 2015) seperti hal nya yang pernah kita rasakan saat ada gempa.

Perbedaan nilai yang tidak terlalu besar dibandingkan penelitian sebelumnya yang dijadikan acuan yaitu peta gempa bumi Indonesia SNI (Nasional, 2012) karena dalam studi penelitian ini menggunakan data gempa-gempa besar terkini yang terjadi di daerah studi penelitian yang mungkin sebelumnya belum digunakan pada penelitian terdahulu. Kemudian data sesar-sesar aktif yang digunakan adalah hasil perhitungan studi geologi terbaru dan perkiraan dari asumsi yang ada. Input parameter yang digunakan dalam analisis seismic hazard ini juga telah menggunakan model sumber gempabumi 3-D yang memiliki fungsi jarak yang lebih nyata.

Kondisi Geologi daerah Jakarta Timur juga memiliki pengaruh dalam percepatan tanah yang terjadi akibat gempa. Sebagian besar daerah Jakarta Timur terdiri dari batuan alluvium seperti tanah lempung/ pasir dan kerikil, bukan batuan keras, sehingga jika terjadi gempabumi, tanah tidak terlalu mengalami pergerakan hebat. Namun hal ini juga menjadi salah satu factor dalam mempengaruhi ketahanan bangunan. Bangunan yang didirikan di atas tanah alluvium harus memiliki pondasi yang kuat dan dalam.

Untuk hasil analisis yang lebih detail, penelitian ini telah menghitung PGA untuk periode ulang 500 tahun di beberapa wilayah di Jakarta Timur seperti Pasar Rebo, Cililitan, Jatinegara, dan Duren Sawit. Detail nilai PGA di daerah-daerah tersebut disajikan dalam Gambar 4.

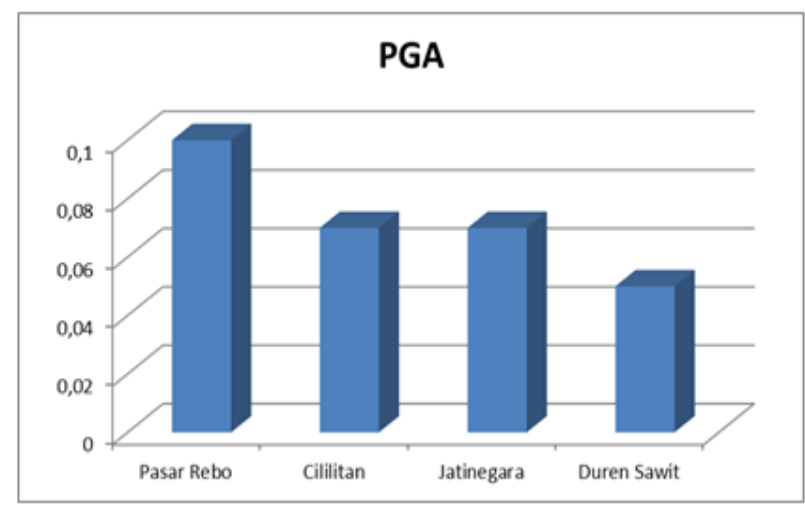

Gambar 4. Detail nilai PGA untuk periode ulang 500 tahun di beberapa kota di Jakarta Timur

Dari Gambar 4 terlihat bahwa Kecamatan Pasar Rebo memiliki nilai PGA paling tinggi. Nilai ini sesuai dengan posisi Pasar Rebo yang berada di Selatan Jakarta Timur. Daerah Jakarta Timur bagian Utara paling kecil nilai PGA nya berdasarkan hasil analisis, oleh karena itu daerah Jakarta Utara seperti Duren Sawit, paling aman untuk mendirikan apartemen berlantai tinggi.

\section{PENUTUP}

\section{Simpulan}

Berdasarkan peta zonasi percepatan gerakan tanah (peta hazard) di wilayah Jakarta Timur yang dihasilkan dari proses PSHA, dapat ditarik kesimpulan sebagai berikut:

1. Untuk periode ulang 500 tahun (10\% PE 50 tahun) nilai PGA $(\mathrm{T}=0$ detik $)$ yang dihasilkan adalah $0,03 \mathrm{~g}-0,15 \mathrm{~g}$,

2. Jakarta Timur merupakan wilayah yang cukup stabil dengan tingkat bahaya gempabumi termasuk rendah.

3. Semakin ke selatan dan barat daya, nilai PGA semakin naik akibat dekat dengan aktivitas subduksi dan vulkanis.

4. nilai PGA dalam penelitian ini hamper sama dari revisi peta gempabumi Indonesia SNI-031726-02 tahun 2010. 
Saran

Untuk penelitian sejenis yang akan dilakukan berikutnya, maka penulis menyarankan peneliti selanjutnya sebaiknya menggunakan data yang lebih banyak dan perlu dilakukan penelitian terbaru tentang sesar-sesar yang aktif di sekitar lokasi penelitian agar mendapatkan hasil yang lebih akurat. Fungsi atenuasi yang digunakan juga diharapkan dapat berasal dari penelitian yang ada di Indonesia, sehingga cocok untuk keadaan tektonik dan geologi Indonesia.

\section{DAFTAR PUSTAKA}

Aldiamar, F. (2013). Evaluasi Peta Percepatan Gempa Sumatera (SNI-1726-2002) Terhadap Peta Percepatan Gempa Menggunakan Software PSHA. Widyariset, 12(1), 7-16.

Katz, G., \& Levin, I. (2015). The Dynamics of Political Support in Emerging Democracies: Evidence from a Natural Disaster in Peru. International Journal of Public Opinion Research, 28(2), 173-195.

Pawirodikromo, Widodo., 2012, Seismologi Teknik dan Rekayasa Kegempaan, Pustaka Pelajar, Yogyakarta.

Nasional, B.S, (2012). Tata cara perencanaan ketahanan gempa untuk struktur bangunan gedung dan non gedung. SNI, 1726, 2012.

Thenhaus, P. and Campbell, K., 2003, Seismic Hazard Analysis Earthquake Engineering Handbook, page 8-1 - 8 50.CRC Press.

USGS, 2007, Seismic Hazard of Western Indonesia, Map prepare by United State of Geology Survey, URL http://earthquake,usgs,gov/research/hazmap/product data/ diunduh pada: jam 08,00 12 Desember 2014. 